\title{
MODELLING OF COMPOSITE SANDWICH STRUCTURES WITH HONEYCOMB CORE SUBJECTED TO HIGH VELOCITY IMPACT
}

\author{
Brenda L. Buitrago ${ }^{*}$, Carlos Santiuste*, Sonia Sánchez-Sáez ${ }^{*}$, Enrique Barbero * and \\ Carlos Navarro* \\ *Department of Continuum Mechanics and Structural Analysis \\ University Carlos III of Madrid \\ Avda. de la Universidad 30, 28911 Leganés, Madrid, Spain \\ e-mail: ebarbero@ing.uc3m.es, web page: http://www.uc3m.es/mma \\ $\dagger$ Department of Industrial Technology \\ Simón Bolivar University \\ Valle de Sartenejas, Caracas, Venezuela
}

Key words: Sandwich structures, numerical simulation, impact, honeycomb

Summary. In this study the behaviour of composite sandwich panels with aluminium honeycomb core subjected to high velocity impact was analysed by a numerical model which was validated by experimental tests.

\section{INTRODUCTION}

Sandwich structures used for weight-efficient components are commonly applied in aerospace applications. The most usual components of aerospace sandwiches are carbon-fibre skins and honeycomb cores. During service, these structures may encounter high-velocity impacts caused by runway stones, hailstones, debris, etc. Most studies on high-velocity impact behaviour of sandwich structures are based on experimental tests [1]. Since impact phenomena depend on numerous parameters such as material properties or projectile geometry, a numerical model, validated experimentally, is necessary to allow the study of the influence of several parameters without making costly experimental tests.

In this work, a numerical model is used to study the behaviour of sandwich panels made of composite skins with aluminium honeycomb core under high-velocity impact. The model was validated by experimental tests.

\section{MATERIAL}

The sandwich skins were made from a carbon/epoxy woven laminate (AS4/8552) $2 \mathrm{~mm}$ thick with a honeycomb core made from aluminium $20 \mathrm{~mm}$ thick.

\section{NUMERICAL MODEL}

For the analysis of the sandwich panel, a numerical model was implemented in ABAQUS/EXPLICIT, 
Figure 1. Only a quarter of the panel was modelled due to the symmetry of the problem. The failure of the skins was evaluated by a criterion implemented in a VUMAT subroutine which includes several failure mechanisms for fibre and matrix [2], also considering delamination failure [3]. To model the loss of composite mechanical properties a degradation procedure and a criterion of element deletion based on strains was included in the subroutine. The honeycomb core was modelled in the zone closest to the impact, reproducing the aluminium hexagonal cells, while the distant zones were modelled by a homogeneous equivalent material. The core model was validated by experimental tests.

\section{EXPERIMENTAL VALIDATION}

To validate the numerical model, experimental tests were carried out by a gas-gun set-up with spherical projectiles of $1.5 \mathrm{gr}$ and $7.5 \mathrm{~mm}$ diameter. The velocity range was between 100 and $550 \mathrm{~m} / \mathrm{s}$. Impact and residual velocities were measured by a high-speed video camera.

\section{RESULTS}

Experimental and numerical results were compared verifying the precision of the model in the prediction of the residual velocity of the projectile. From this information the ballistic limit could be estimated with less than $1 \%$ error. The model also predicts the failure shape and the contribution of each component of the sandwich panel to the energy absorption of the projectile. The honeycomb core-energy absorption was estimated to be very small compared with skins ones.
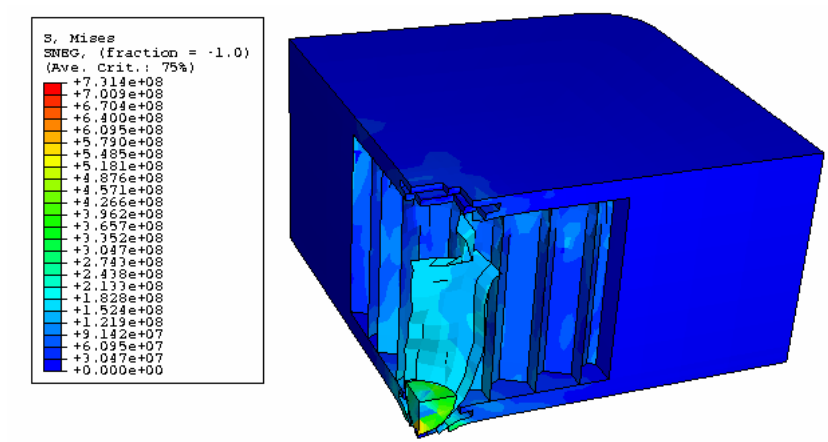

Figure 1: Modelling of the perforation of the sandwich plate

\section{REFERENCES}

[1] GR. Villanueva and WJ. Cantwell, "the high velocity impact response of composite and fml-reinforced sandwich structures", Composites Science and Technology, 64, 35-54 (2004)

[2] F. Chang and K. Chang, "A progressive damage model for laminated composites containing stress concentrations", Journal of Composite Materials, 21, 834-855 (1987)

[3] JC. Brewer and PA Lagace, "Quadratic stress criterion for initiation of delamination", Journal of Composite Materials, 22, 1141-1155 (1988) 